Dear author,

Please note that changes made in the online proofing system will be added to the article before publication but are not reflected in this PDF.

We also ask that this file not be used for submitting corrections. 
Research Report

\title{
Brain activation profiles during kinesthetic and visual imagery: An fMRI study
}

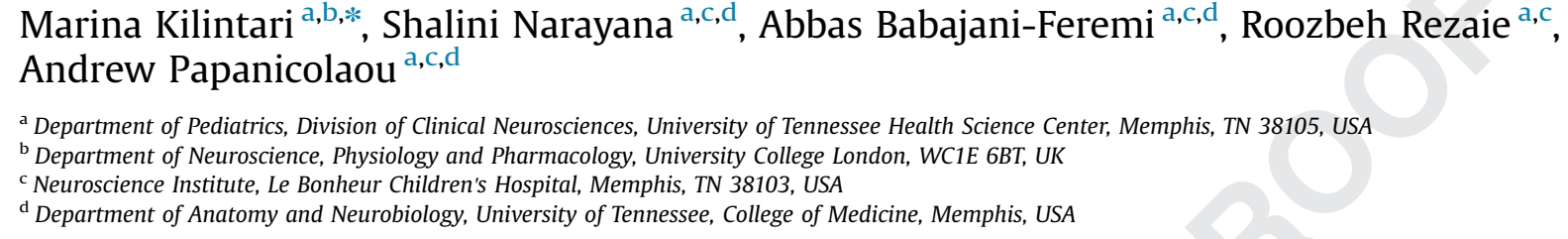

\section{A R T I C L E I N F O}

\section{Article history:}

Received 19 October 2015

Received in revised form

9 May 2016

Accepted 7 June 2016

\section{Keywords:}

Motor imagery

Kinesthetic imagery

Visual imagery

Embodied cognition

fMRI

\begin{abstract}
A B S T R A C T
The aim of this study was to identify brain regions involved in motor imagery and differentiate two alternative strategies in its implementation: imagining a motor act using kinesthetic or visual imagery. Fourteen adults were precisely instructed and trained on how to imagine themselves or others perform a movement sequence, with the aim of promoting kinesthetic and visual imagery, respectively, in the context of an fMRI experiment using block design. We found that neither modality of motor imagery elicits activation of the primary motor cortex and that each of the two modalities involves activation of the premotor area which is also activated during action execution and action observation conditions, as well as of the supplementary motor area. Interestingly, the visual and the posterior cingulate cortices show reduced BOLD signal during both imagery conditions. Our results indicate that the networks of regions activated in kinesthetic and visual imagery of motor sequences show a substantial, while not complete overlap, and that the two forms of motor imagery lead to a differential suppression of visual areas.
\end{abstract}

(c) 2016 Published by Elsevier B.V.

\section{Introduction}

In the context of theories of embodied cognition, motor imagery $(\mathrm{MI})$ is said to involve fundamentally the same neuronal circuit as the execution of complex voluntary acts (e.g. Decety, 1996; Jeannerod, 1995; Jeannerod and Decety, 1995; Jeannerod and Frak, 1999). In the case of hand movements like finger tapping, this circuit involves, among other brain structures, the region corresponding to the arm and hand representation in the primary motor (M1) and somatosensory (S1) cortex of the contralateral hemisphere, the premotor cortex (Witt et al., 2008) and, in the case of self-initiated actions, the supplementary motor area (SMA) (Nachev et al., 2008). The suggestion that imagined actions are likely to involve the same circuit as actually executed (and observed) ones is based on the notion that a motor image is the conscious representation of a non-executed action (Jeannerod, 1994, 1995).

\footnotetext{
* Correspondence to: Department of Neuroscience, Physiology and Pharmacology, University College London, Gower Street, WC1E 6BT London, UK.

E-mail addresses: m.kilintari@ucl.ac.uk (M. Kilintari), snaraya2@uthsc.edu (S. Narayana), ababajan@uthsc.edu (A. Babajani-Feremi), rrezaie@uthsc.edu (R. Rezaie), apapanic@uthsc.edu (A. Papanicolaou).
}

There is ample evidence that imagined actions bear the same temporal regularities and the same responsiveness to physical laws as their overt counterparts (Anquetil and Jeannerod, 2007; Decety et al., 1989; Sirigu et al., 1995a,b) and that real and imagined hand movements share partially overlapping neuronal networks (Ehrsson et al., 2003; Gerardin et al., 2000; Lotze et al., 1999; Nair et al., 2003; Porro et al., 2000; Roth et al., 1996; Sharma et al., 2008). However, despite the general consensus regarding regional overlap between imagery and sensory processing, there is disagreement concerning the set of areas that support the generation of mental motor representations and, more so, when subjects have to form these representations adopting different perspectives (Hetu et al., 2013). An important area whose involvement in motor imagery has been repeatedly debated is the primary motor cortex (M1) (Dechent et al., 2004; Guillot et al., 2012; Hetu et al., 2013).

There are several factors that can account for the discrepancies concerning the set of areas activated during motor imagery and the activation of M1 in particular (Dechent et al., 2004; Hetu et al., 2013; Lotze and Halsband, 2006). It has been suggested that the lack of agreement among studies could be due to the inadequate sensitivity of the neuroimaging methods to capture small or transient activations (e.g. Dechent et al., 2004; Hetu et al., 2013). 
Specifically, that the whole brain analysis that is used in many studies, may be inadequate to capture such activations and a regions of interest (ROI) approach may be a more sensitive method (Hetu et al., 2013); or, as it has been suggested that the usually employed general linear model has limitations which may be surpassed using multivariate models (e.g. Norman et al., 2006; Peelen and Downing, 2007; Sauvage et al., 2011). A second reason for the diversity of the results could be the type of action that subjects are imagining. For example, imagery of simple movements may or may not recruit different neuronal populations than imagery of complex motor acts (e.g. Gerardin et al., 2000) as could imagining novel versus skilled, overlearned movements (e.g. Lacourse et al., 2005).

Another, quite plausible reason for the discrepancies in the literature, may be the strategy employed during performance of the task. Imagining an action can involve visual, kinesthetic or both imagery strategies (e.g. Guillot et al., 2009; Madan and Singhal, 2012). One may engage predominantly in "external visual imagery" meaning that one imagines someone else performing the imagined action (Callow and Hardy, 2004; Fourkas et al., 2006; Lorey et al., 2009; Moran, 2009; Ramsey et al., 2010) which coincides with what others call imagery from the third person perspective (e.g. Jackson et al., 2006; Holmes and Calmels, 2008; Guillot et al., 2009). Alternatively one may engage instead in "internal visual imagery" involving imagining oneself performing the action. However, as many investigators have commented (e.g. Ruby and Decety, 2001; Callow and Hardy, 2004; Lorey et al., 2009; Jiang et al., 2015), this form of strategy may confound visual and kinesthetic imagery. More explicitly, when people resort to such a strategy they may imagine the sensation one experiences during performance of an act (kinesthetic imagery) or visualize themselves performing this act as being the spectators of their own actions (visual imagery). Consequently, instructions to the subjects to either visualize themselves performing the act or to use kinesthetic imagery and imagine themselves moving in the appropriate way (e.g. Jiang et al., 2015) are essential to avoid complicating interpretation of the neuroimaging data.

Reviewing the relevant literature one can find many examples that demonstrate how different strategies applied by subjects may introduce ambiguity in the interpretation of the results. For example, Leonardo et al. (1995) used a simple finger-to-thumb opposition movement and asked their participants to imagine themselves performing this action. This study does not clarify the strategy the participants used and the general statement (i.e. "... imagine themselves performing...") does not allow us to appraise their finding of activation of the contralateral sensorimotor cortex. Similarly, Lotze et al. (1999) found M1 activation when they asked their participants to imagine forming a fist without explicitly reporting the imagery strategy that was used. Later studies too, in which the motor imagery modality was not specified, also replicated the finding of M1 activation (e.g. Diers et al., 2010). On the other hand, other studies where it was also not specified whether the participants adopted the kinesthetic or visual strategy during the internal imagery, did not report activation of M1 in the imagery condition. In one such study, the researchers used simple and complex flexion/extension finger movements and asked the participants to imagine performing these movements (Gerardin et al., 2000).

Equally puzzling results are also observed in studies where the modality of imagery is specified. For example, Porro et al. (1996) reported increased activation in M1 during mental representation of sequential finger movements, when the instructions for motor imagery were "to imagine using the right hand to perform movements and feeling the sensations associated with fingertapping", therefore urging the participants to employ both visual and kinesthetic imagery. Furthermore, studies in which participants used only kinesthetic imagery (e.g. Guillot et al., 2008; Zhang et al., 2011) do find activation of M1, perhaps pointing to the direction that kinesthetic rather than visual imagery is essential for recruiting M1. However, the same data indicate that M1 recruitment may depend on the different imagery capabilities of the participants and not on the specific type of imagery (Guillot et al., 2008). On the other hand, there is accumulated evidence that M1 is not recruited either in the visual or in the kinesthetic imagery (e.g. Stephan et al., 1995; Hanakawa et al., 2008; Guillot et al., 2009; Fleming et al., 2010; Chang et al., 2011; Szameitat et al., 2012). Moreover, whether kinesthetic or visual imagery is adopted depends on how well subjects may have already developed their internal motor representations (e.g. Olsson et al., 2008).

Therefore, a major challenge in imaging the circuits that mediate imagining motor acts is the choice of the appropriate experimental design as well as the specification of the kind of mental imagery subjects are to engage in during scanning, given the many and varied imagination strategies people are able to adopt.

The aforementioned studies are few examples in the vast literature on motor imagery which indicate that we have yet to reach a solid conclusion regarding the network that is consistently activated during motor imagery, and whether this network involves M1, in particular. In fact, a recent meta-analysis of 122 motor imagery experiments (from 75 papers) reports that only 22 of them mention activation of M1 and 100 do not (Hetu et al., 2013).

To minimize such confounds and maximize the use of either kinesthetic imagery while subjects imagined themselves performing an act or visual imagery when asked to imagine someone else performing the act, we trained our subjects in these two strategies using concrete examples of an act they had first to actually perform and actually observe during an execution and observation condition. Specifically, to reduce the uncertainty associated with the strategy used during motor imagery tasks, it was necessary to provide individuals with concrete examples of precisely what is to be imagined. Accordingly, we trained a group of participants to perform finger tapping movements and then to imagine performing the same movements (kinesthetic imagery). Moreover, we instructed them to observe the same videotaped action performed by someone else and immediately afterwards to imagine what they had just observed (visual imagery). This way, by specifying the strategies that individuals adopt in performing tasks, one could probably identify the cortical regions that are differentially activated in the two modalities, and the possible contribution of the primary motor cortex in each case Fig. 1.

\section{Results}

As detailed in Table 1 and in Fig. 2(a), for the condition of action execution, the entire sensory-motor circuit, including the contralateral premotor, motor, somatosensory and parietal cortices, was significantly activated as expected (Witt et al., 2008). In particular, activations were observed in the primary motor and somatosensory cortices (BA 4 and BA 2/3) at the level of representation of the upper limb, the dorsal and ventral parts of the premotor cortex (BA 6), the inferior parietal area BA 39, the prefrontal areas BA 8 and BA 9, as well as in frontal areas BA 46 and BA 47. Visual areas BA 17 and BA 18 were significantly activated bilaterally, since the execution task was carried out with the eyes open whereas the control condition with the eyes closed. Finally, action execution induced activations in the cerebellum ipsilateral to the moving hand as well as in the contralateral putamen of the basal ganglia.

For the condition of action observation (see Table 2 and Fig. 2 (b)), significant activations were found in the primary visual cortex (BA 17) as well as in the middle and inferior occipital gyri (BA 18 


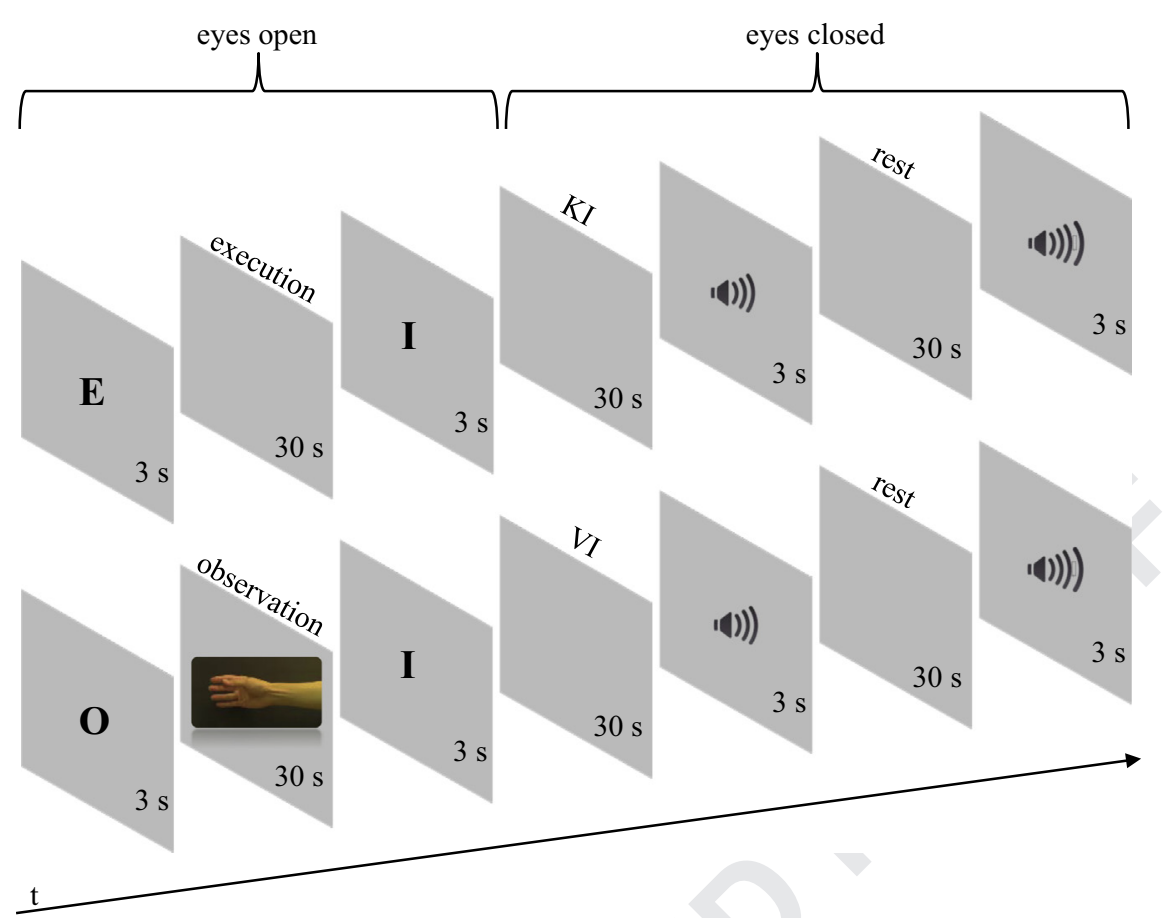

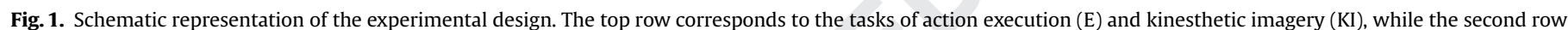

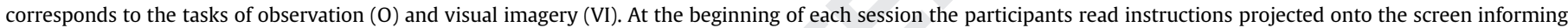

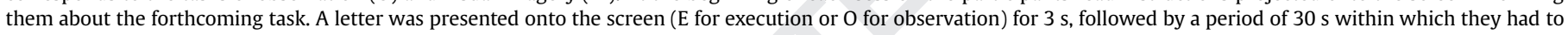

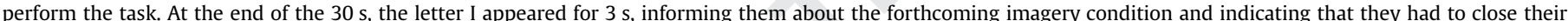

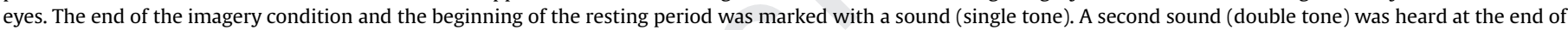
the resting period, indicating that the participants had to open their eyes and get ready to repeat the task.

and BA 19), as expected from the visual stimulation due to the presentation of the video clip in this condition. More importantly, regions comprising the sensory-motor circuit were also activated. These areas included the dorsal and the ventral part of premotor cortex BA 6 (BA 6d and BA $6 \mathrm{v}$ respectively) in the hemisphere contralateral to the observed hand, the inferior parietal lobules BA $39 / 40$ bilaterally and the superior parietal lobule BA 7 in the hemisphere ipsilateral to the observed hand. At this point we should mention that while assigning the coordinates of the local maxima to Brodmann areas using the Multi-image Analysis GUI, a point located in the fringe of the cluster encompassing premotor cortex BA 6, was attributed to BA 4. This local maximum lies only marginally in the border of the cluster corresponding to M1 activated during the execution task, and its coordinates do not correspond to the hand representation during motor imagery found in previous fMRI studies (Ehrsson et al., 2003; Hlustik et al., 2001). We believe that this point belongs to area BA 6 and the assignment is due to a slight mis-localization evident at the borderline of the two areas. Thus, we marked this triad of coordinates as BA 6/4 to denote this fact. Additionally, as in the case of action execution, increased activity was also found in BA 8 bilaterally. Also area BA 10 was significantly activated in the left hemisphere of the observer, i.e. contralateral to the presented (right) moving arm. Finally, bilaterally activated was BA 37, which includes the extrastriate body area (EBA) (Astafiev et al., 2004; Downing et al., 2001).

The two imagery conditions yielded distinct activation profiles as compared to the rest condition. For the condition of kinesthetic motor imagery, significant clusters of activation were found in the premotor area (BA 6) centring on its dorsal (BA 6d), ventral (BA 6v) and medial (SMA) parts, as well as in the cingulate gyrus (BA 24), mostly contralateral to the imagined hand. In addition, the inferior parietal area BA 40 was activated bilaterally whereas the superior parietal cortex (BA 7) was activated contralateral to the imagined hand (see Fig. 2(c)). The coordinates of the local maxima of the activated clusters are detailed in Table 3. As in the case of action observation, one local maximum belonging to the cluster spanning BA 6 was attributed to area BA 4, because it was located at the fringe of the cluster bordering area BA 4 . We marked this point as BA 6/4. Nonetheless, the area corresponding to the hand representation in BA 4 was not activated during kinesthetic imagery.

Visual imagery of movement as compared to the resting state activated only the dorsal (BA 6d) and the medial (SMA) parts of the premotor cortex whereas its ventral part (BA $6 \mathrm{v}$ ) remained unaffected. The activation of BA $6 \mathrm{~d}$ was bilateral as opposed to the kinesthetic imagery condition in which this area was activated only in the hemisphere contralateral to the imagined moving hand. Yet, as in the case of kinesthetic imagery, the inferior parietal cortex (BA 40) was activated bilaterally (Fig. 2(d) and Table 4).

An interesting feature of the brain activity pattern during imagining movement using either kinesthetic or visual imagery was the deactivation of the visual cortex and the posterior cingulate which was revealed by comparing the rest condition with each one of them (rest versus kinesthetic imagery and rest versus visual imagery).

Specifically, activity in the visual areas BA 17, BA 18 and BA 19 was decreased bilaterally during kinesthetic imagery as compared to the rest condition although the eyes of the participants were closed during both the imagery and the rest conditions. Moreover, parts of the retrosplenial and posterior cingulate cortex as well as of the subgenual anterior cingulate cortex (BA 30, 31, 32, 25) were also less activated along with BA 11 and regions in the left thalamus and in the right cerebellum (see Table 5 and Fig. 3). Similarly, visual areas BA 17, BA 18 and BA 19, BA 37, were also found to be de-activated bilaterally during visual imagery as compared to the rest condition; as were parts of the right cerebellum and thalamus (Table 6 and Fig. 4). Finally, clusters that were de-activated during visual imagery as compared to the rest condition were evident in BA 11 in the hemisphere ipsilateral to the imagined moving hand, 
1 Table 1

2 Results of group analysis showing significantly activated clusters during action execution versus rest.

\begin{tabular}{|c|c|c|c|c|c|}
\hline \multirow[t]{2}{*}{ Brain area } & \multicolumn{3}{|c|}{ Coordinates } & \multirow[t]{2}{*}{$\mathbf{L} / \mathbf{R}$} & \multirow[t]{2}{*}{ z score } \\
\hline & $\mathbf{x}$ & $\mathbf{y}$ & $\mathbf{z}$ & & \\
\hline BA 4 & -38 & -16 & 54 & $\mathrm{~L}$ & 4.98 \\
\hline BA 2 & -48 & -20 & 44 & $\mathrm{~L}$ & 4.94 \\
\hline BA 3 & -54 & -16 & 44 & $\mathrm{~L}$ & 4.73 \\
\hline BA 3 & -38 & -24 & 52 & $\mathrm{~L}$ & 4.74 \\
\hline BA 6 (dorsal) & -36 & -12 & 68 & $\mathrm{~L}$ & 4.72 \\
\hline BA 6 (dorsal) & -8 & 34 & 56 & $\mathrm{~L}$ & 4.01 \\
\hline BA 6 (ventral) & -54 & 4 & 30 & $\mathrm{~L}$ & 5.00 \\
\hline BA 8 & -24 & 22 & 48 & $\mathrm{~L}$ & 4.23 \\
\hline BA 8 & -18 & 24 & 48 & $\mathrm{~L}$ & 3.97 \\
\hline BA 8 & -10 & 50 & 40 & $\mathrm{~L}$ & 3.92 \\
\hline BA 8 & -16 & 28 & 44 & $\mathrm{~L}$ & 4.6 \\
\hline BA 9 & -10 & 62 & 22 & $\mathrm{~L}$ & 3.94 \\
\hline BA 46 & -48 & 44 & -6 & $\mathrm{~L}$ & 4.42 \\
\hline BA47 & -36 & 46 & -6 & $\mathrm{~L}$ & 3.73 \\
\hline BA 39 & -44 & -56 & 36 & $\mathrm{~L}$ & 3.80 \\
\hline BA 39 & -50 & -58 & 28 & $\mathrm{~L}$ & 3.79 \\
\hline BA 39 & -54 & -62 & 24 & $\mathrm{~L}$ & 3.65 \\
\hline BA 39 & -56 & -62 & 30 & $\mathrm{~L}$ & 3.87 \\
\hline BA 39 & -50 & -64 & 36 & $\mathrm{~L}$ & 3.73 \\
\hline BA 39 & -46 & -72 & 36 & $\mathrm{~L}$ & 3.48 \\
\hline BA 17 & -4 & -92 & 2 & $\mathrm{~L}$ & 3.69 \\
\hline BA 17 & 4 & -98 & 4 & $\mathrm{R}$ & 3.71 \\
\hline BA 17 & 0 & -88 & 12 & $\mathrm{~m}$ & 3.79 \\
\hline BA 18 & -2 & -98 & 8 & $\mathrm{~L}$ & 3.56 \\
\hline BA 18 & 4 & -98 & 10 & $\mathrm{R}$ & 3.68 \\
\hline BA 18 & 4 & -82 & 12 & $\mathrm{R}$ & 3.61 \\
\hline Cerebellum & 6 & -62 & -18 & $\mathrm{R}$ & 4.07 \\
\hline Cerebellum & 8 & -58 & -18 & $\mathrm{R}$ & 4.02 \\
\hline Cerebellum & 16 & -54 & -22 & $\mathrm{R}$ & 4.83 \\
\hline Cerebellum & 24 & -58 & -28 & $\mathrm{R}$ & 4.01 \\
\hline Cerebellum & 6 & -64 & -26 & $\mathrm{R}$ & 4.00 \\
\hline Putamen & -30 & -16 & -2 & $\mathrm{~L}$ & 4.31 \\
\hline Putamen & -28 & -12 & 2 & $\mathrm{~L}$ & 4.27 \\
\hline Putamen & -28 & -8 & -6 & $\mathrm{~L}$ & 3.97 \\
\hline Putamen & -30 & -26 & -2 & $\mathrm{~L}$ & 3.80 \\
\hline Putamen & -26 & 4 & 6 & $\mathrm{~L}$ & 3.67 \\
\hline Putamen & -28 & 2 & -4 & $\mathrm{~L}$ & 3.44 \\
\hline
\end{tabular}

List of the locations of the significantly activated clusters in the condition of action execution as compared to the control resting condition. Columns $\mathrm{x}, \mathrm{y}, \mathrm{z}$ refer to the coordinates of the maxima within each cluster in MNI space. L, left hemisphere; $\mathrm{m}$, midline; $\mathrm{R}$, right hemisphere. All clusters are significant at $\mathrm{p}<0.01$ (corrected).

and in posterior and anterior cingulate areas BA 31/32/25 and in parahippocampal area BA 27 mostly in the contralateral hemisphere (Table 6 and Fig. 4).

To address the question as to how the brain activation patterns of the two imagery conditions differed, we directly compared kinesthetic imagery with visual imagery.

The only statistically significant difference in the two activation patterns (Table 7 and Fig. 5) was the higher suppression of activity in the visual cortices (BA 17, 18, 19, and 37) in the condition where the participants imagined someone else executing the action, in contrast to the kinesthetic imagery. The opposite comparison (visual imagery minus kinesthetic imagery) did not yield any statistical significant differences.

\section{Discussion}

The aim of the present study was to identify the profiles of brain activation associated with two imagery modalities, i.e. kinesthetic and visual imagery, during a finger tapping task and also to examine the involvement of the primary motor cortex in either one or both of these two conditions.

The use of the execution and observation tasks as prototypes for the kinesthetic and visual imagery allowed us to verify that the activation profiles we obtained of these two conditions accord with those reported in the literature. The agreement of our results with those published in most relevant neuroimaging studies (see e.g. Witt et al., 2008) reassured us of the soundness of our fMRI results. Specifically, as shown in Table 1 and in Fig. 2(a), for the condition of action execution, the entire sensory-motor circuit, including activation of the cerebellum ipsilateral to the moving hand was significantly activated as did the visual cortex since the task was carried out with the eyes open.

During action observation the visual cortex was also activated, as were regions belonging to the sensory-motor circuit such as the dorsal and the ventral part of premotor cortex BA 6 contralateral to the observed hand, the inferior parietal lobules bilaterally and the superior parietal lobule in the hemisphere ipsilateral to the observed hand. These results accord well with a recent meta-analysis which shows that dorsal and ventral premotor areas, and the inferior and superior parietal lobules are involved in action observation (Molenberghs et al., 2012), as well as with the notion of embodied cognition (Jeannerod, 1995; Jeannerod and Decety, 1995; Jeannerod and Frak, 1999; Jeannerod, 2001; Wilson, 2002; Anderson, 2003; Ziemke, 2003) in the sense that it involves, besides visual areas regions of the brain containing the hubs of the circuit participating in the performance of voluntary movements. The primary motor and somatosensory cortices did not show significant activation for the observation condition. However bilateral activation was observed in BA 37, which includes the extrastriate body area (EBA) (Astafiev et al., 2004; Downing et al., 2001; Taylor and Downing, 2011). EBA does not respond only in viewing images of the human body (Urgesi et al., 2004; Taylor et al., 2007), but also to limb movements to visual targets, even in the absence of visual feedback from the movement (Astafiev et al., 2004). Such results have raised the question of whether EBA is influenced differentially by one's own or another person's movements and whether it may serve as an identification system where the discrimination of self/other is achieved. In concert with that notion it has been suggested that the right EBA contains separate neuronal sub-populations that are selectively sensitive to images of our own or others' body parts (Myers and Sowden, 2008) and that it processes body identity (Urgesi et al., 2007). However, this hypothesis has not been supported consistently by the experimental data as it has been shown that although EBA activity is increased significantly for allocentric relative to egocentric views, it is not influenced by identity and does not show differential activation for distinctions between familiar or unfamiliar bodies or recognition of one's own body (Chan et al., 2004; Hodzic et al., 2009). Additionally, using TMS it has been shown that interference with the EBA impairs the discrimination of bodily forms, whereas the discrimination of bodily actions is impaired with interference in ventral premotor cortex (Urgesi et al., 2007). Therefore, taking a conservative perspective on our results we conclude that EBA's activation during action observation is compatible with the notion that is related to allocentric views and that is not specialized to attribute actions to the correct agent.

Distinct activation profiles were found in the two imagery conditions. During kinesthetic imagery, activation was found in dorsal premotor (BA 6d) and ventral (BA 6v) premotor cortex, in parts of the medial SMA and in the cingulate gyrus, mostly contralateral to the imagined hand, the inferior parietal area bilaterally and in the superior parietal cortex contralateral to the imagined hand (see Fig. 2(c)).

During the condition of visual imagery activations were found in only the dorsal premotor area bilaterally (as opposed to the contralateral activation during the kinesthetic imagery condition) and in the medial parts of the supplementary motor cortex but not in the ventral premotor area and, as in the case of kinesthetic 



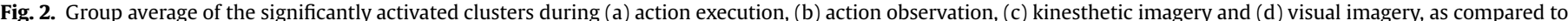

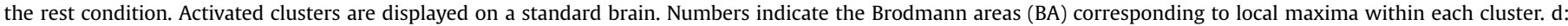

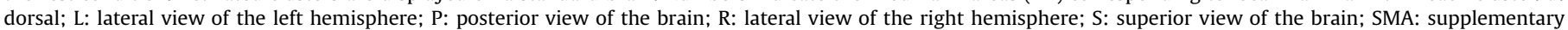
motor area; v - ventral.

imagery, in the inferior parietal cortex (Fig. 2(d) and Table 4).

In the well-known study by Ruby and Decety (2001) when the participants imagined themselves acting, increased activation was evident in the left inferior parietal lobe, precentral gyrus, the SMA, the occipito-temporal junction (MT/V5) and the anterior insula. Our results agree with these findings as far as activation of the core areas is concerned (inferior parietal lobe, precentral gyrus and SMA). However, the activations we observed were not limited to the left hemisphere but were bilateral. Similarly, in the condition where subjects were instructed to imagine the experimenter acting activation was found in the left precentral gyrus, pre-SMA, MT/V5 and in the right inferior parietal lobule. Here again we found bilateral activation that did not include MT/V5.
Other studies have supported the idea of a left hemispheric dominance for one's own actions and action simulation (Vogeley and Fink, 2003). Yet whether lateralized or bilateral activation is in fact required remains rather unclear since there is evidence that support both alternatives. For example, in one study in which right-handed participants practised both imagery modalities, the SMA/PMC were bilaterally activated and VPMC was found active only in the right hemisphere (Lorey et al., 2009), while evidence has also emerged showing that bilateral parietal lesions result in complete unawareness of executing finger movements during imagery (Schwoebel et al., 2002). Other studies have also shown that several other areas such as the precuneus and the prefrontal cortex were bilaterally activated (e.g. Daselaar et al., 2010). 
1 Table 2

2 Results of group analysis showing significantly activated clusters during action 3 observation versus rest.

\begin{tabular}{|c|c|c|c|c|c|}
\hline \multirow[t]{2}{*}{ Brain area } & \multicolumn{3}{|c|}{ Coordinates } & \multirow[t]{2}{*}{$\mathbf{L} / \mathbf{R}$} & \multirow[t]{2}{*}{ z score } \\
\hline & $\mathbf{x}$ & $\mathbf{y}$ & $\mathbf{z}$ & & \\
\hline BA $6 / 4$ & -54 & -2 & 44 & $\mathrm{~L}$ & 4.54 \\
\hline BA 6 (ventral) & -58 & 0 & 32 & $\mathrm{~L}$ & 4.06 \\
\hline BA 6 (border of dorsal and ventral) & -54 & -6 & 34 & $\mathrm{~L}$ & 3.44 \\
\hline BA 6 (dorsal) & -52 & -6 & 38 & $\mathrm{~L}$ & 3.40 \\
\hline BA 6 (dorsal) & -50 & 6 & 48 & $\mathrm{~L}$ & 3.88 \\
\hline BA 6 (dorsal) & -52 & 8 & 38 & $\mathrm{~L}$ & 3.52 \\
\hline BA 6 (dorsal) & -22 & 18 & 54 & $\mathrm{~L}$ & 3.94 \\
\hline BA 6 (dorsal) & -16 & 32 & 50 & $\mathrm{~L}$ & 3.88 \\
\hline BA 6 (dorsal) & -8 & 30 & 64 & $\mathrm{~L}$ & 3.77 \\
\hline BA 6 (dorsal) & 20 & 32 & 54 & $\mathrm{R}$ & 4.25 \\
\hline BA 6 (dorsal) & 6 & 42 & 54 & $\mathrm{R}$ & 3.72 \\
\hline BA 6 (dorsal) & 14 & 38 & 58 & $\mathrm{R}$ & 3.59 \\
\hline BA 6 (dorsal) & 12 & 36 & 54 & $\mathrm{R}$ & 3.53 \\
\hline BA 6 (dorsal) & 26 & 28 & 56 & $\mathrm{R}$ & 3.49 \\
\hline BA 8 & -2 & 42 & 52 & $\mathrm{~L}$ & 4.24 \\
\hline BA 8 & -4 & 48 & 40 & $\mathrm{~L}$ & 4.12 \\
\hline BA 8 & -6 & 54 & 46 & $\mathrm{~L}$ & 3.86 \\
\hline BA 8 & 16 & 42 & 48 & $\mathrm{R}$ & 3.58 \\
\hline BA 10 & -44 & 44 & 4 & $\mathrm{~L}$ & 4.22 \\
\hline BA 10 & -26 & 54 & -4 & $\mathrm{~L}$ & 3.37 \\
\hline BA $10 / 47$ & -36 & 54 & -6 & $\mathrm{~L}$ & 3.96 \\
\hline BA 7 & 20 & -60 & 62 & $\mathrm{R}$ & 4.23 \\
\hline BA 7 & 30 & -62 & 58 & $\mathrm{R}$ & 3.98 \\
\hline BA 7 & 26 & -58 & 66 & $\mathrm{R}$ & 3.82 \\
\hline BA 7 & 34 & -50 & 64 & $\mathrm{R}$ & 3.65 \\
\hline BA 39 & -54 & -64 & 34 & L & 4.33 \\
\hline BA 39 & -52 & -66 & 28 & $\mathrm{~L}$ & 4.26 \\
\hline BA 39 & -46 & -64 & 30 & $\mathrm{~L}$ & 4.03 \\
\hline BA 39 & -50 & -60 & 42 & $\mathrm{~L}$ & 4.02 \\
\hline BA 40 & -46 & -50 & 48 & $\mathrm{~L}$ & 4.33 \\
\hline BA 40 & -36 & -50 & 56 & $\mathrm{~L}$ & 4.09 \\
\hline BA 40 & 42 & -48 & 54 & $\mathrm{R}$ & 4.25 \\
\hline BA 40 & 46 & -44 & 58 & $\mathrm{R}$ & 4.20 \\
\hline BA 37 & -46 & -68 & 10 & L & 4.27 \\
\hline BA 37 & 46 & -68 & 6 & $\mathrm{R}$ & 4.68 \\
\hline BA 17 & -18 & -98 & 8 & $\mathrm{~L}$ & 4.62 \\
\hline BA 17 & -10 & -94 & -2 & L & 4.89 \\
\hline BA 17 & 26 & -90 & 2 & $\mathrm{R}$ & 5.07 \\
\hline BA 18 & -26 & -94 & 12 & $\mathrm{~L}$ & 4.72 \\
\hline BA 19 & -44 & -82 & -2 & $\mathrm{~L}$ & 4.72 \\
\hline
\end{tabular}

List of the locations of the significantly activated clusters in the condition of action observation as compared to the control resting condition. Columns $\mathrm{x}, \mathrm{y}, \mathrm{z}$ refer to the coordinates of the maxima within each cluster in MNI space. L, left hemisphere; $\mathrm{R}$, right hemisphere. All clusters are significant at $\mathrm{p}<0.01$ (corrected).

The engagement of the parietal cortex in both imagery conditions is consistent with neuroimaging findings indicating that the inferior and superior parietal lobules are activated during mental simulation of movements (Binkofski et al., 2000; Decety et al., 1994; Filimon et al., 2007; Fleming et al., 2010; Gerardin et al., 2000; Grafton et al., 1996; Grezes and Decety, 2001; Stephan et al., 1995). Additionally our finding that the superior and inferior parietal areas are involved in motor imagery is consistent with neuropsychological studies reporting that parietal lesions affect patient's ability to form mental images (Heilman et al., 1982; Sirigu et al., 1995a,b, 1996), while a recent meta-analysis, combining the data of 54 studies, revealed that the superior and inferior parietal lobules are consistently recruited during imagery of upper limb movements (Hetu et al., 2013). Additionally, our finding that BA 7 is only activated during kinesthetic imagery is in agreement with evidence that the superior parietal lobe has a key role in sensorimotor integration, by actively maintaining an internal representation of one's own body (Wolpert et al., 1998).

Neither imagery condition in our study induced activation of the EBA. This is consistent with the aforementioned meta-analyses which showed that the EBA is not included in the activations
Table 3.

67

Results of group analysis showing significantly activated clusters during kinesthetic imagery versus rest.

\begin{tabular}{lrrrll}
\hline Brain area & \multicolumn{2}{l}{ Coordinates } & & L/R & z score \\
\cline { 2 - 4 } & $\mathbf{x}$ & $\mathbf{y}$ & $\mathbf{z}$ & & \\
\hline BA 6/4 & -52 & -6 & 48 & $\mathrm{~L}$ & 4.14 \\
BA 6 (dorsal) & -54 & -4 & 38 & $\mathrm{~L}$ & 4.28 \\
BA 6 (SMA) & -2 & 0 & 66 & $\mathrm{~L}$ & 4.97 \\
BA 6 (SMA) & -8 & 0 & 68 & $\mathrm{~L}$ & 4.81 \\
BA 6 (SMA) & -4 & 4 & 64 & $\mathrm{~L}$ & 4.75 \\
BA 6 (SMA) & 4 & 4 & 58 & $\mathrm{R}$ & 3.13 \\
BA 6 (dorsal) & -50 & -2 & 36 & $\mathrm{~L}$ & 4.06 \\
BA 6 (ventral) & -50 & -2 & 28 & $\mathrm{~L}$ & 3.68 \\
BA 6 (ventral) & -56 & 2 & 26 & $\mathrm{~L}$ & 3.64 \\
BA 7 & -30 & -48 & 52 & $\mathrm{~L}$ & 4.05 \\
BA 7 & -24 & -52 & 56 & $\mathrm{~L}$ & 3.54 \\
BA 40 & -52 & -32 & 46 & $\mathrm{~L}$ & 4.03 \\
BA 40 & -54 & -34 & 50 & $\mathrm{~L}$ & 3.90 \\
BA 40 & -34 & -40 & 46 & $\mathrm{~L}$ & 3.50 \\
BA 40 & -48 & -36 & 54 & $\mathrm{~L}$ & 3.48 \\
BA 40 & 42 & -28 & 44 & $\mathrm{R}$ & 4.18 \\
BA 40 & 50 & -26 & 48 & $\mathrm{R}$ & 4.04 \\
BA 40 & 40 & -30 & 38 & $\mathrm{R}$ & 4.02 \\
BA 40 & 50 & -28 & 36 & $\mathrm{R}$ & 3.87 \\
BA 40 & 42 & -34 & 56 & $\mathrm{R}$ & 3.36 \\
BA 48 & 32 & -26 & 34 & $\mathrm{R}$ & 3.61 \\
BA 24 & -10 & 12 & 44 & $\mathrm{~L}$ & 3.28 \\
BA 24 & -8 & 8 & 48 & $\mathrm{~L}$ & 3.40 \\
\hline
\end{tabular}

List of the locations of the significantly activated clusters in the condition of kinesthetic imagery as compared to the control resting condition. Columns $\mathrm{x}, \mathrm{y}, \mathrm{z}$ refer to the coordinates of the maxima within each cluster in MNI space. L, left hemisphere; R, right hemisphere. All clusters are significant at $\mathrm{p}<0.01$ (corrected)

Table 4

Results of group analysis showing significantly activated clusters during visual imagery versus rest.

\begin{tabular}{lrrrrr}
\hline Brain area & \multicolumn{2}{l}{ Coordinates } & & L/R & \multirow{2}{*}{ z score } \\
\cline { 2 - 4 } & $\mathbf{x}$ & $\mathbf{y}$ & $\mathbf{z}$ & & \\
\hline BA 6 (SMA) & -6 & 0 & 64 & $\mathrm{~L}$ & 5.38 \\
BA 6 (dorsal) & -26 & -14 & 60 & $\mathrm{~L}$ & 4.35 \\
BA 6 (dorsal) & 26 & -4 & 58 & $\mathrm{R}$ & 4.67 \\
BA 40 & -40 & -42 & 50 & $\mathrm{~L}$ & 4.58 \\
BA 40 & -44 & -36 & 42 & $\mathrm{~L}$ & 4.15 \\
BA 40 & -40 & -38 & 58 & $\mathrm{~L}$ & 4.09 \\
BA 40 & -42 & -30 & 42 & $\mathrm{~L}$ & 3.96 \\
BA 40 & -42 & -30 & 50 & $\mathrm{~L}$ & 3.84 \\
BA 40 & -54 & -34 & 44 & $\mathrm{~L}$ & 3.81 \\
BA 40 & 48 & -28 & 58 & $\mathrm{R}$ & 4.30 \\
BA 40 & 42 & -30 & 46 & $\mathrm{R}$ & 4.26 \\
BA 40 & 40 & -34 & 44 & $\mathrm{R}$ & 3.24 \\
\hline
\end{tabular}

List of the locations of the significantly activated clusters in the condition of visual imagery as compared to the control resting condition. Columns $\mathrm{x}, \mathrm{y}, \mathrm{z}$ refer to the coordinates of the maxima within each cluster in MNI space. L, left hemisphere; $\mathrm{R}$, right hemisphere. All clusters are significant at $\mathrm{p}<0.01$ (corrected).

consistently present during kinesthetic and visual imagery (Hetu et al., 2013). Moreover the absence of EBA activation during visual imagery of motor actions implies that whereas EBA may participate in the discrimination of egocentric and allocentric views during action observation, motor imagery may be accomplished by a circuit that does not include the EBA but may include the posterior parietal cortex (Burgess, 2008).

The effects of motor imagery differ from those of action-execution in several ways that are detailed below, mainly in that they do not involve activation of the primary motor cortex. As we have already discussed, the recruitment of M1 in motor imagery is still debated with the majority of the studies not reporting it (Hetu 
Table 5.

Clusters at group level analysis showing decreases in the BOLD signal during kinesthetic imagery.

\begin{tabular}{|c|c|c|c|c|c|}
\hline \multirow[t]{2}{*}{ Brain area } & \multicolumn{3}{|c|}{ Coordinates } & \multirow[t]{2}{*}{$\mathbf{L} / \mathbf{R}$} & \multirow[t]{2}{*}{ z score } \\
\hline & $\mathbf{x}$ & $\mathbf{y}$ & $\mathbf{z}$ & & \\
\hline BA 17 & -12 & -100 & 10 & $\mathrm{~L}$ & 3.80 \\
\hline BA 18 & -6 & -88 & 26 & $\mathrm{~L}$ & 4.44 \\
\hline BA 18 & -20 & -104 & 2 & $\mathrm{~L}$ & 4.37 \\
\hline BA 18 & 10 & -96 & 24 & $\mathrm{R}$ & 5.24 \\
\hline BA 19 & -4 & -94 & 32 & $\mathrm{~L}$ & 4.28 \\
\hline BA 19 & 10 & -94 & 30 & $\mathrm{R}$ & 4.84 \\
\hline BA 11 & -10 & 30 & -16 & $\mathrm{~L}$ & 3.98 \\
\hline BA 11 & 8 & 40 & -22 & $\mathrm{R}$ & 3.82 \\
\hline BA 25 & 8 & 22 & -20 & $\mathrm{R}$ & 4.27 \\
\hline BA 30 & 4 & -72 & 10 & $\mathrm{R}$ & 4.29 \\
\hline BA 31 & -6 & -36 & 40 & $\mathrm{~L}$ & 4.14 \\
\hline BA 31 & 8 & -36 & 42 & $\mathrm{R}$ & 4.48 \\
\hline BA 31 & 0 & -42 & 46 & $\mathrm{~m}$ & 4.09 \\
\hline BA 32 & -10 & 36 & -18 & $\mathrm{~L}$ & 3.91 \\
\hline BA 32 & 8 & 36 & -18 & $\mathrm{R}$ & 3.78 \\
\hline Caudate & -14 & 26 & -8 & $\mathrm{~L}$ & 3.91 \\
\hline Cerebellum & 6 & -58 & -34 & $\mathrm{R}$ & 3.80 \\
\hline Cerebellum & 8 & -58 & -24 & $\mathrm{R}$ & 3.52 \\
\hline Cerebellum & 4 & -60 & -24 & $\mathrm{R}$ & 3.35 \\
\hline Cerebellum & 0 & -58 & -42 & $\mathrm{~m}$ & 4.27 \\
\hline Thalamus & -18 & -28 & -6 & $\mathrm{~L}$ & 4.49 \\
\hline Thalamus & -18 & -24 & -2 & $\mathrm{~L}$ & 4.40 \\
\hline Thalamus & -22 & -26 & -4 & $\mathrm{~L}$ & 4.34 \\
\hline
\end{tabular}

List of the locations of the significantly de-activated clusters in the condition of kinesthetic imagery as compared to the resting condition. Columns $\mathrm{x}, \mathrm{y}, \mathrm{z}$ refer to the coordinates of the maxima within each cluster in MNI space. L, left hemisphere; $\mathrm{m}$, midline; $\mathrm{R}$, right hemisphere. All clusters are significant at $\mathrm{p}<0.01$ (corrected).

et al., 2013). Our results agree with these studies. Therefore, even when using concrete examples of the imagery tasks and even if the instructions for assuming the appropriate perceptual modality are explicitly stated and rehearsed, imagination of a common, relatively simple hand action does not elicit activation in M1. As other researchers have also thought, our hypothesis, in the context of the theory of shared mechanisms between motor action and motor representation, was that the two imagery conditions would differ in M1 activation, in the sense that the integration of sensorimotor information is more relevant while adapting kinesthetic imagery than in the visual imagery condition (Lorey et al., 2009).
Table 6.

Clusters at group level analysis showing decreases in the BOLD signal during visual imagery.

\begin{tabular}{|c|c|c|c|c|c|}
\hline \multirow[t]{2}{*}{ Brain area } & \multicolumn{3}{|c|}{ Coordinates } & \multirow[t]{2}{*}{$\mathbf{L} / \mathbf{R}$} & \multirow[t]{2}{*}{ z score } \\
\hline & $\mathbf{x}$ & $\mathbf{y}$ & $\mathbf{z}$ & & \\
\hline BA 17 & -16 & -98 & 10 & $\mathrm{~L}$ & 5.22 \\
\hline BA 17 & 22 & -90 & 8 & $\mathrm{R}$ & 5.14 \\
\hline BA 18 & -24 & -100 & 12 & $\mathrm{~L}$ & 5.49 \\
\hline BA 19 & -28 & -92 & 14 & $\mathrm{~L}$ & 5.44 \\
\hline BA 19 & -30 & -84 & 14 & $\mathrm{~L}$ & 4.94 \\
\hline BA 19 & -24 & -92 & 30 & $\mathrm{~L}$ & 4.89 \\
\hline BA 19 & -44 & -76 & 2 & $\mathrm{~L}$ & 4.10 \\
\hline BA 19 & 45 & -76 & 6 & $\mathrm{R}$ & 4.53 \\
\hline BA 37 & -39 & -73 & 4 & $\mathrm{~L}$ & 3.89 \\
\hline BA 37 & 44 & -69 & 4 & $\mathrm{R}$ & 4.26 \\
\hline BA 11 & 2 & 34 & -20 & $\mathrm{R}$ & 4.07 \\
\hline BA 25 & 0 & 22 & -20 & $\mathrm{~m}$ & 4.17 \\
\hline BA 27 & 22 & -30 & -4 & $\mathrm{R}$ & 3.87 \\
\hline BA 31 & -2 & -44 & 36 & $\mathrm{~L}$ & 3.46 \\
\hline BA 31 & 10 & -46 & 36 & $\mathrm{R}$ & 4.00 \\
\hline BA 32 & -10 & 32 & -14 & $\mathrm{~L}$ & 4.42 \\
\hline BA 32 & 6 & 36 & -14 & $\mathrm{R}$ & 4.25 \\
\hline BA 32 & 10 & 38 & -16 & $\mathrm{R}$ & 4.25 \\
\hline BA 32 & 0 & 28 & -18 & $\mathrm{~m}$ & 4.29 \\
\hline Cerebellum & 2 & -56 & -50 & $\mathrm{R}$ & 4.09 \\
\hline Cerebellum & 0 & -60 & -48 & $\mathrm{~m}$ & 4.07 \\
\hline Cerebellum & 2 & -60 & -56 & $\mathrm{R}$ & 3.70 \\
\hline Cerebellum & 2 & -56 & -40 & $\mathrm{R}$ & 3.61 \\
\hline Thalamus & 18 & -30 & 4 & $\mathrm{R}$ & 4.16 \\
\hline Thalamus & 14 & -26 & -4 & $\mathrm{R}$ & 3.82 \\
\hline Thalamus & 14 & -28 & 10 & $\mathrm{R}$ & 3.40 \\
\hline
\end{tabular}

List of the locations of the significantly de-activated clusters in the condition of visual imagery as compared to the resting condition. Columns $\mathrm{x}, \mathrm{y}, \mathrm{z}$ refer to the coordinates of the maxima within each cluster in MNI space. L, left hemisphere; $\mathrm{m}$, midline; $R$, right hemisphere. All clusters are significant at $\mathrm{p}<0.01$ (corrected).

This conjecture is compatible with studies which indicated that kinesthetic imagery might naturally, or even obligatorily, involve motor activation, while visual imagery might operate using preferentially non-motor mechanisms (Sirigu and Duhamel, 2001).

Yet, according to our results it seems that the imagery strategy is not the crucial factor for the involvement of M1 in motor imagery of a simple hand action suggesting that other factors such as those discussed in the introduction (the personal ability to form
67




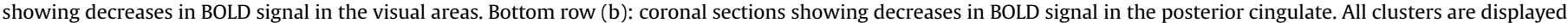
on a standard brain. Numbers indicate the Brodmann areas corresponding to local maxima within each cluster. Abbreviations according to Fig. 2. 

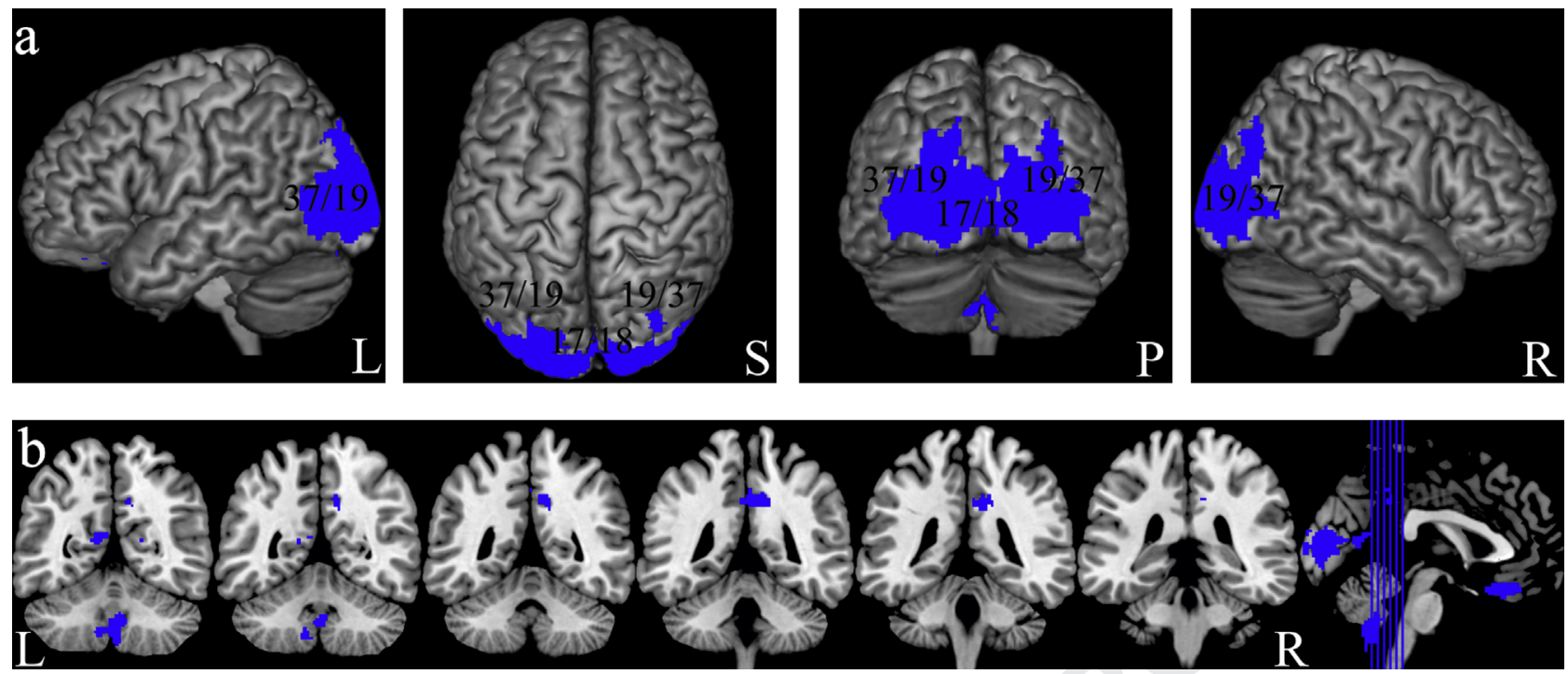

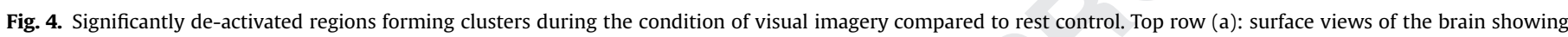

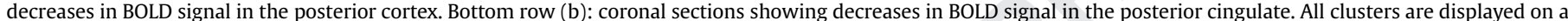
standard brain. Numbers indicate the Brodmann areas corresponding to local maxima within each cluster. Abbreviations according to Fig. 2.

Table 7.

Differences in degree of de-activation between the conditions of kinesthetic and visual imagery.

\begin{tabular}{|c|c|c|c|c|c|}
\hline \multirow[t]{2}{*}{ Brain area } & \multicolumn{3}{|c|}{ Coordinates } & \multirow[t]{2}{*}{$\mathbf{L} / \mathbf{R}$} & \multirow[t]{2}{*}{ z score } \\
\hline & $\mathbf{x}$ & $\mathbf{y}$ & $\mathbf{z}$ & & \\
\hline BA 17 & -10 & -102 & 2 & $\mathrm{~L}$ & 3.99 \\
\hline BA 17 & -18 & -96 & 6 & $\mathrm{~L}$ & 3.55 \\
\hline BA 18 & -8 & -94 & -6 & $\mathrm{~L}$ & 3.59 \\
\hline BA 18 & -22 & -98 & 14 & $\mathrm{~L}$ & 3.52 \\
\hline BA 18 & -12 & -92 & -10 & $\mathrm{~L}$ & 3.38 \\
\hline BA 19 & -26 & -88 & 14 & $\mathrm{~L}$ & 3.95 \\
\hline BA 19 & 52 & -78 & 0 & $\mathrm{R}$ & 3.60 \\
\hline BA 19 & 44 & -74 & 0 & $\mathrm{R}$ & 3.59 \\
\hline BA 37 & 48 & -72 & 10 & $\mathrm{R}$ & 3.92 \\
\hline BA 37 & 42 & -70 & 2 & $\mathrm{R}$ & 3.76 \\
\hline BA 37 & 52 & -68 & -8 & $\mathrm{R}$ & 3.45 \\
\hline BA37 & 42 & -64 & -2 & $\mathrm{R}$ & 3.17 \\
\hline
\end{tabular}

List of the locations that differ in the degree of de-activation in MNI-space coordinates (columns $\mathrm{x}, \mathrm{y}, \mathrm{z}$ ) in the conditions of kinesthetic and visual imagery. L, left hemisphere; $\mathrm{R}$, right hemisphere. All clusters are significant at $\mathrm{p}<0.01$ (corrected).

and retrieve mental representations, the requirements of the action or the expertise of the participants; Kuhtz-Buschbeck et al., 2003; Olsson et al., 2008; Lotze and Zentgraf, 2010) may determine involvement of M1. For example, it has been suggested that increasing experience in motor imagery induces changes to the activation patterns involving less motor areas and more areas implicated in abstract representations (Lotze and Halsband, 2006). Moreover, it has been shown that M1 is not active in skilled musicians during imagined performance (Langheim et al., 2002) also suggesting that the performance of a well-known and familiar hand action may recruit efficiently stored mental representations without the explicit need of recruiting the sensorimotor cortex.

Nonetheless, our results are in agreement with previously reported imaging results which support the notion that motor cognition is accomplished by activating one's own sensorimotor system (Filimon et al., 2007, 2014; Grafton, 2009; Grezes and Decety, 2001) and in line with the embodied nature of motor cognition in the sense that several hubs of the circuit mediating execution of movements, also subserve motor imagery (Dinstein et al., 2008; Hickok, 2009; Jeannerod, 2001). Future studies may overcome the design limitations of the present one and by systematically exploring the aforementioned factors such as that of personal skill or degree of complexity of the imagined action, may provide a more cogent explanation of the partial activation of the action execution circuit during motor imagery.

Apart from the absence of activation in the area of hand representation in M1 during motor imagery, another prominent feature that differentiates motor imagination from overt action is the activation of the SMA. The activation of the SMA both for the visual and the kinesthetic imagery, in contrast to its lack of activation for execution of the same movement in our study, could
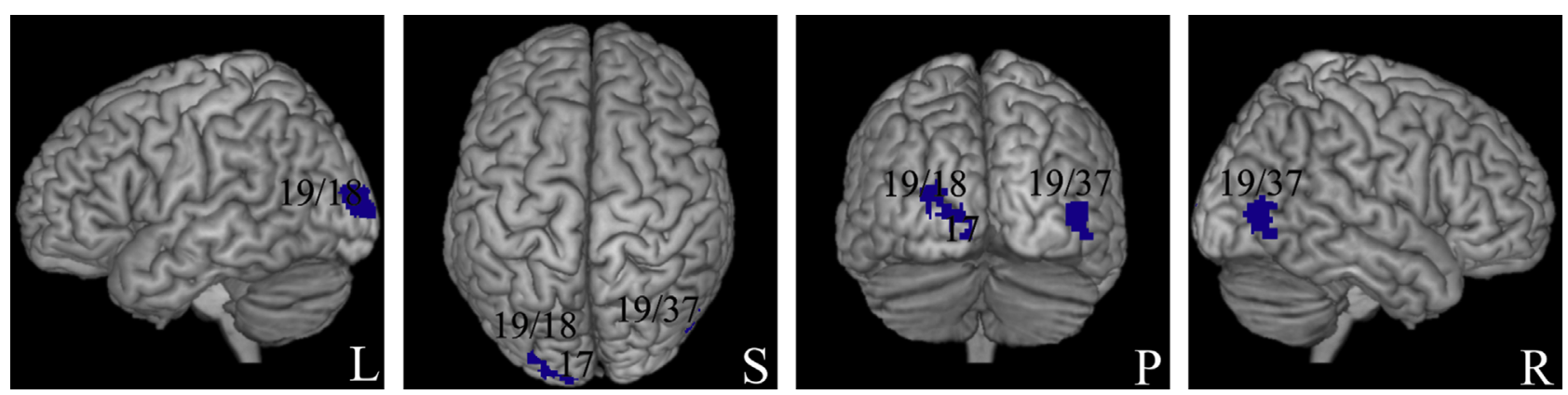



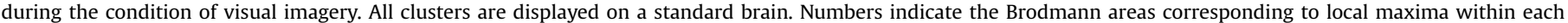
cluster. Abbreviations according to Fig. 2. 
reflect a possible inhibitory role of this area, controlling movement cancellation. Actually, a correlation between the neuronal activity within the SMA and both the proactive and reactive control of arm movements has been demonstrated in monkeys (Chen et al., 2010), while proactive inhibitory control of movement was found in humans (Jaffard et al., 2008). Therefore, the SMA was said to mediate unconscious inhibition of voluntary actions (Albares et al., 2014; Boy et al., 2010; Sumner et al., 2007) and to exert a suppressive influence on M1 in motor imagery (Kasess et al., 2008). It is therefore possible that the activation of the SMA in both types of motor imagery in our study may represent inhibitory influence on the primary motor cortex, thus avoiding performance of movements during internal representation of action. On the other hand, the absence of activation in the SMA during action observation indicates that movement cancellation is mediated by a different mechanism when visual information is available (i.e. when the action is overt).

Additionally, activation of SMA during imagery in our study is compatible with the role of this area in controlling internally referenced motor responses (self-initiated movements) rather than responses to external events (for reviews see Goldberg (1985), Haggard (2008) and Nachev et al. (2008)). It is also compatible with lesion data showing that lesions of the lateral premotor cortex lead to impairment of correct retrieval of movements in accordance with appropriate visual cues (Halsband and Passingham, 1985; Passingham, 1985), whereas lesions in the SMA disrupt the retrieval of self-initiated movements (Passingham et al., 1989). Indeed, it has been reported that when subjects have to imagine externally paced hand movements, the SMA does not show higher activation (Lotze et al., 1999). We should also mention that our finding that the SMA is specifically activated during imagery confirms an early well known study, which described activation of this area when subjects "internally" simulated a motor sequence without actually executing the movements (Roland et al., 1980).

Another intriguing aspect of the brain activity pattern during both imagination conditions was the apparent deactivation of the visual cortex and the posterior cingulate that emerged from contrasting the rest condition with each one of them. The deactivation of the visual cortex in both imagery conditions is a counterintuitive finding. Following some early imaging studies (e.g. Kosslyn et al., 1993, 1995) the belief was established that imagination is mediated by the same brain areas as perception. However, our results indicate that imagining motor actions as opposed imagining static scenes may not involve the same mechanisms as the latter, a conclusion supported by other studies of motor imagery (e.g. Ruby and Decety, 2001; Filimon et al., 2007) showing lack of activation in the occipitotemporal cortex. Interestingly, a study by Daselaar et al. (2010) has shown that the primary visual cortex was suppressed during visual imagery. They proposed that this suppression helped the processing of internally-generated images by shielding the associative sensory regions from external perceptual input processed by the primary visual regions.

A further noteworthy finding in our study was the de-activation of the posterior cingulate cortex in both imagery conditions as compared to the rest control condition (Figs. 3(b) and 4(b)). The posterior cingulate cortex can be either considered an important hub of the default mode network (DMN) (Buckner et al., 2008) or parts of it can be identified as belonging to the posterior cingulate motor areas (Amiez and Petrides, 2014). However, neither interpretation of the function of the posterior cingulate could explain the observed decrease in its activation during imagery tasks in our study: first, because in introspection tasks like retrieval and imagery the DMN network is expected to show activation rather than the reverse (Laird et al., 2011; Hassabis et al., 2007) and our task was akin to those that enhance DMN activation. In fact, it has been shown that the posterior cingulate cortex shows modality- independent activation during both visual and auditory imagery (Daselaar et al., 2010). Second, were we to consider the posterior cingulate as part of the motor circuit it would be again more plausible for it to show increased activity when individuals are imagining motor actions, as was in fact the case in a study by Ruby and Decety (2001).

The direct contrast between the two imagery conditions, performed in order to address the question as to how activation differed between them, revealed greater degree of suppression of activity in the visual cortex in the condition where the participants imagined the experimenter performing the action which was unexpected since this form of imagery is thought to engage mainly a visual strategy (Guillot et al., 2009), as opposed to kinesthetic imagery which is expected to involve primarily somatosensory and motor resources.

These negative BOLD responses merit further exploration, and their interpretation may be other than neuronal activity suppression (Hayes and Huxtable, 2012). Indeed, a study that examined the coupling of local electroencephalographic (EEG) oscillations with the positive/negative BOLD responses of simultaneously recorded data, found that positive BOLD responses were correlated to features of the EEG signal whereas negative BOLD responses were not (Yuan et al., 2011). Other researchers though have demonstrated that negative BOLD responses are tightly coupled to neuronal activity decreases (Shmuel et al., 2006). Therefore the import of visual response suppression in our study may or may not indicate inhibition of the visual areas during imagery. The limitations of the presently used experimental design, which was not intended to provide evidence for particular alternative explanations for such an unanticipated result may be overcome by future designs explicitly addressing the phenomenon of the relative visual cortex deactivation during visual imagery.

In conclusion, we did not see an exact overlap of active brain regions for movement execution and imagery; nonetheless imagining the performance of complex motor acts whether employing a visual or a kinesthetic modality does involve important hubs of the motor circuit such as the premotor and supplementary motor areas and in that sense it is in accordance with the embodied theory of motor cognition, verifying that imaging a movement engages motor processing resources (Jeannerod, 1995, 2001; Jeannerod and Decety, 1995; Jeannerod and Frak, 1999). The neuronal networks for imagination and execution are not equivalent, with the main difference being the absence of activation in the primary motor cortex for the imagination tasks. Therefore our results are in line with the majority of neuroimaging which do not detect activation of this area during imagery (Hetu et al., 2013). Additionally, our results demonstrate the only difference between the brain activation patterns sustaining the process of imagining using visual or kinesthetic imagery is the degree of deactivation of visual areas. Whether other aspects also differentiate the two conditions could not be discerned on the basis of the BOLD response of the brain during these two conditions.

\section{Materials and methods}

\subsection{Subjects}

Fourteen adults of both genders ( 4 men and 10 women between 18 and 41 years of age) without history of neurological or psychiatric disorders and with normal vision were recruited through campus-wide advertisement. All subjects were righthanded as assessed by the Edinburgh handedness scale (Oldfield, 1971). Each subject participated in one training session and one fMRI session. All subjects signed a written informed consent prior to their participation, and were compensated for their time. The 
study was approved by the Institutional Review Board of the University of Tennessee Health Science Center.

\subsection{Stimuli and experimental design}

The action that we used to implement our experimental design was a sequential finger-to-thumb opposition movement, one of the most commonly used to study the human motor system in the functional neuroimaging literature. This action is intentional, fairly complex, requires attention, can be performed within the confined space of an fMRI scanner and yields minimum movement artifacts. The exact sequence consisted of opposing digit 1 (thumb) sequentially to digits 2-5 (index to little finger) forwards and in reverse order. Thus the thumb-finger opposition sequence was 2 , $3,4,5,5,4,3,2$.

We used a block design with fixed block-length for the fMRI recordings. Given the complexity of the two imagery conditions and the difficulty in switching from task to task, a block design was better suited for the purpose, although rapid mixed event-related fMRI designs are often applied (D'Esposito et al., 1999). In fact, while conducting pilot tests, the subjects that participated in that phase reported that they could not switch rapidly from one imagery modality to the other. This feedback was decisive in our choice of design. The experimental paradigm, illustrated in detail in Fig. 1, consisted of two pairs of conditions: (i) in the first pair, an execution task in which subjects performed the sequential finger tapping movement with their right hand (execution condition) was followed by the condition of kinesthetic imagery in which the participants had to imagine themselves performing the action; (ii) in the second pair, a video clip of an actor's right hand executing the same finger tapping task was presented to the participants (observation condition), and after that the participants had to imagine the movement they had just seen, i.e. the external agent performing the movement (visual imagery). In the condition of kinesthetic imagery, participants were explicitly instructed to imagine that they were tapping their fingers as they previously did in the execution condition and to imagine the somatosensory effect of their movement. Since the participants' position in the MRI scanner did not allow them to see their hand during the execution condition, our instructions were to focus on kinesthetic aspects of the movement. In the condition of visual imagery, the instructions were to imagine the sequential finger tapping as it was performed by the experimenter in the video clip they had watched, therefore employ visual imagery of the movement performed by the external agent. A resting period of time followed each imagery condition. The duration of all conditions was $30 \mathrm{~s}$.

The video clip used in the observation condition was recorded with a digital camera and edited in VideoPad Video Editor (Version 3.14, NCH Software). The hand was filmed executing the movement sequence on a black background, and only the forearm appeared in all frames and was projected on a screen inside the fMRI scanner, at the center of the subjects' visual field, to facilitate direct viewing without unnecessary eye movements. The order of presentation of the pairs of tasks was randomized across the subjects. Visual cues presented on the same screen ("E" for execution, "O" for observation, "I" for imagery) informed the subject for the onset of each $30 \mathrm{~s}$ task period, whereas an auditory cue (single tone) announced the end of the imagery tasks and the beginning of the resting period. The subjects were instructed to keep their eyes closed (1) during the imagery conditions (as soon as the letter "I" appeared on the screen) in order to maximize their ability to mentally represent the finger tapping, and (2) during the resting period when they were instructed to avoid thinking about the movement. Finally, another auditory cue (double tone) informed the subjects that the resting period was over and that they had to open their eyes and repeat the task. The duration of each pair of tasks including the rest condition was 10.2 min and consisted of six iterations of each $30 \mathrm{~s}$ trial for each task.

Both the actor in the video clip and the participants in the execution condition performed the action in the absence of any external pacing stimulus (i.e., self-paced at a frequency of $\sim 1 \mathrm{~Hz}$ ) with their dominant (right) hand. Participants were instructed to keep the same pace in the two imagery conditions, matching the pace in the execution and observation conditions (and we ensured that they were capable of doing so in the training session - see Section 4.3 "Experimental procedure"). Since it has been demonstrated that the rate effect of repetitive simple movements in healthy subjects is not a source of variability in fMRI signal for task frequencies ranging from 0.2 to $2 \mathrm{~Hz}$ (Diciotti et al., 2007), it is unlikely that the rate effect had any significant impact on our results. The subjects were asked to remain motionless during all three motor cognition tasks (observation, visual and kinesthetic imagery) and the resting periods, and move only the fingers of their right hand during the execution task.

\subsection{Experimental procedure}

\subsubsection{Training sessions}

In order to evaluate the participants' imagery ability and to ensure that they could perform the tasks accurately, the subjects partook in a training session outside the scanner the day prior to experimental (scanning) sessions. During the first phase of the training session the participants were sited in front of a computer screen and they were trained in all four tasks, and practiced relaxation with their eyes closed in preparation for the rest condition. The specific requirements of all experimental conditions were described to them in detail, and prior to the second phase of the training session, the participants had few test runs while sitting in front of the screen, where we ascertained that they were capable of forming mental representation of actions by asking them to describe their experience, rate their ability to keep pace, their ability to keep a constant mental image, their ability to alternate between conditions, and their ability to use consistently either kinesthetic or visual imagery by having them rate their compliance with the task instructions. Only participants that described their ability to comply as good and very good advanced in the second phase of the training session. After these preliminary test runs, the eligible subjects participated in the formal training session which was identical to the actual experimental session they would do the following day, in which they were again tested for their compliance. The feedback for this second phase was given at the end of the test. If a participant failed in this second phase, he/she was excluded. We excluded one participant during this procedure as she did not alternate successfully between the experimental conditions. During these training sessions, electromyograms (EMGs) were acquired from the subjects' right and left first dorsal interossei, abductor pollicis brevis and adductor digiti minimi muscles, to ascertain that no movements of the hands were inadvertently performed during all except the execution condition.

\subsubsection{Experimental sessions}

Structural and functional MR images were obtained on a $3 \mathrm{~T}$ scanner (Siemens Verio, Siemens AG, Munich, DE) with a 12-channel head coil. High-resolution anatomical images were acquired using a MP-RAGE sequence $\left(\mathrm{TR} / \mathrm{TE} / \mathrm{flip}\right.$ angle $=2300 \mathrm{~ms} / 3.66 \mathrm{~ms} / 13^{\circ}$ ) with slice-select inversion recovery pulses $(\mathrm{TI}=751 \mathrm{~ms}), \mathrm{FOV}=512 \times 512 \times 176$, and $0.5 \times 0.5 \times 1 \mathrm{~mm}$ spatial resolution. A $\mathrm{T} 2 *$-weighted gradient-echo echo-planar-imaging BOLD-fMRI was acquired in block design. The scan parameters were $\mathrm{TR}=3000 \mathrm{~ms}, \mathrm{TE}=30 \mathrm{~ms}$, flip angle $=90^{\circ}, 10$ volumes acquired for each $30 \mathrm{~s}$ paradigm iteration and 215 volumes during the approximately 11-min paradigm $(2.55 \mathrm{~mm} \times 2.55 \mathrm{~mm} \times 3.5 \mathrm{~mm}$ voxels).

During the experimental sessions the subjects were carefully 
monitored by means of a camera to ensure that they remained still and refrained from moving their hands and fingers during the observation, imagery and rest conditions. Additionally, the head was always stabilized by means of foam pads around it. After the experimental session the participants were asked once more to describe their ability to perform the two imagery conditions and assess their engagement in the task. All subjects reported that they had executed the imagery tasks according to the instructions and their previous training, that they employed constantly kinesthetic and visual imagery in the corresponding conditions, and that they were vividly engaged in the task.

\section{4. fMRI data processing}

fMRI data were processed using FEAT (FMRI Expert Analysis Tool) Version 6.00 part of FSL (FMRIB Software Library; http://fsl. fmrib.ox.ac.uk/fsl/) (Worsley, 2001), by fitting a general linear model to determine differences in activation profiles during task and rest conditions, on an individual basis (subject-wise analysis) and across subjects (group analysis) using mixed effects analysis. In order to reveal the activated brain areas during all different conditions, four contrasts relative to the rest condition were performed: (i) execution of finger tapping compared with rest; (ii) observation of finger tapping compared with rest; (iii) kinesthetic imagery of finger tapping compared with rest; and (iv) visual imagery of finger tapping compared with rest. Additionally, the two imagery conditions were compared directly to each other, (i.e. kinesthetic imagery versus visual imagery, and visual imagery versus kinesthetic). Moreover, in order to reveal possible areas of depressed activity during motor imagery, the rest condition was compared with the two imagery conditions (i.e., rest versus kinesthetic imagery, and rest versus visual imagery).

Prior to statistical analysis, the data were preprocessed and corrected for slice timing and motion artifacts using MCFLIRT (Jenkinson et al., 2002), and non-brain tissue was removed using BET (Smith et al., 2002). In addition, spatial smoothing using a Gaussian kernel of FWHM 5mm, and intensity normalization were performed. High pass temporal filtering was also applied to the data (Gaussian-weighted least-squares straight line fitting, with sigma $=50.0 \mathrm{~s})$. Statistical parametric images of z scores (SPM $\{z\})$ were generated and thresholded for $\mathrm{a} z \geq 3$ at a cluster significance threshold of $\mathrm{p}<0.01$ (corrected applying a Gaussian Random Field Theory correction) (Chumbley and Friston, 2009; Worsley, 2001). The functional and high-resolution anatomical data were registered to the MNI152 atlas in standard space using FLIRT (Jenkinson et al., 2002; Jenkinson and Smith, 2001). Finally, the MNI coordinates of the maxima of the significantly activated clusters were assigned to the corresponding Brodmann areas using the template image (in MNI coordinates) provided in the Multi-image Analysis GUI (Mango) (http://ric.uthscsa.edu/mango/).

\section{Acknowledgments}

This work was supported by the action "ARISTEIA II" of the Operational Program "Education and Lifelong Learning" (Action's Beneficiary: General Secretariat for Research and Technology), co4 financed by the European Social Fund and the Greek State. Dr. Marina Kilintari was supported by the Action "Supporting Postdoctoral Researchers" of the Operational Program "Education and Lifelong Learning" (Action's Beneficiary: General Secretariat for Research and Technology), co-financed by the European Social Fund (ESF) and the Greek State.

The authors would like to kindly acknowledge the support of the Shainberg Foundation and the Neuroscience Institute, Le
Bonheur Children's Hospital (http://www.lebonheur.org/our- ser vices/neuroscience-institute/), as well as the expert technical assistance of Dr. Asim F. Choudhri, Miss Katherine Schiller and Mrs. Liliya Birg.

\section{References}

Albares, M., Lio, G., Criaud, M., Anton, J.L., Desmurget, M., Boulinguez, P., 2014. The dorsal medial frontal cortex mediates automatic motor inhibition in uncertain contexts: evidence from combined fMRI and EEG studies. Hum. Brain Mapp. 35 5517-5531.

Amiez, C., Petrides, M., 2014. Neuroimaging evidence of the anatomo-functional organization of the human cingulate motor areas. Cereb. Cortex 24, 563-578. Anderson, M.L., 2003. Embodied cognition: a field guide. Artif. Intell. 149, 91-130.

Anquetil, T., Jeannerod, M., 2007. Simulated actions in the first and in the third person perspectives share common representations. Brain Res. 1130, 125-129.

Astafiev, S.V., Stanley, C.M., Shulman, G.L., Corbetta, M., 2004. Extrastriate body area in human occipital cortex responds to the performance of motor actions. Nat. Neurosci. 7, 542-548.

Binkofski, F., Amunts, K., Stephan, K.M., Posse, S., Schornmann, T., Freund, H., Zilles, K., Seitz, R.J., 2000. Broca's region subserves imagery of motion: a combined cytoarchitectonic and fMRI study. Hum. Brain Mapp. 11, 273-285.

Boy, F., Husain, M., Singh, K.D., Sumner, P., 2010. Supplementary motor area activations in unconscious inhibition of voluntary action. Exp. Brain Res. 206, $441-448$.

Buckner, R.L., Andrews-Hanna, J.R., Schacter, D.L., 2008. The brain's default network. Ann. N.Y. Acad. Sci. 1124, 1-38.

Burgess, N., 2008. Spatial cognition and the brain. Ann. N.Y. Acad. Sci. 1124, 77-97. Callow, N., Hardy, L., 2004. The relationship between the use of kinaesthetic imagery and different visual imagery perspectives. J. Sports Sci. 22, 167-177.

Chan, A.W., Peelen, M.V., Downing, P.E., 2004. The effect of viewpoint on body representation in the extrastriate body area. Neuroreport 15, 2407-2410.

Chang, Y., Lee, J.J., Seo, J.H., Song, H.J., Kim, Y.T., Lee, H.J., Kim, H.J., Lee, J., Kim, W., Woo, M., Kim, J.G., 2011. Neural correlates of motor imagery for elite archers. NMR Biomed. 24, 366-372.

Chen, X., Scangos, K.W., Stuphorn, V., 2010. Supplementary motor area exerts proactive and reactive control of arm movements. J. Neurosci. 30, 14657-14675.

Chumbley, J.R., Friston, K.J., 2009. False discovery rate revisited: FDR and topological inference using Gaussian random fields. Neuroimage 44, 62-70.

Daselaar, S.M., Porat, Y., Huijbers, W., Pennartz, C.M., 2010. Modality-specific and modality-independent components of the human imagery system. Neuroimage 52, 677-685.

D’Esposito, M., Zarahn, E., Aguirre, G.K., 1999. Event-related functional MRI: implications for cognitive psychology. Psychol. Bull. 125, 155-164.

Decety, J., 1996. The neurophysiological basis of motor imagery. Behav. Brain Res. $77,45-52$.

Decety, J., Jeannerod, M., Prablanc, C., 1989. The timing of mentally represented actions. Behav. Brain Res. 34, 35-42.

Decety, J., Perani, D., Jeannerod, M., Bettinardi, V., Tadary, B., Woods, R., Mazziotta, J. C., Fazio, F., 1994. Mapping motor representations with positron emission tomography. Nature 371, 600-602.

Dechent, P., Merboldt, K.D., Frahm, J., 2004. Is the human primary motor cortex involved in motor imagery? Brain Res. Cogn. Brain Res. 19, 138-144.

Diciotti, S., Gavazzi, C., Della Nave, R., Boni, E., Ginestroni, A., Paoli, L., Cecchi, P., De Stefano, N., Mascalchi, M., 2007. Self-paced frequency of a simple motor task and brain activation. An fMRI study in healthy subjects using an on-line monitor device. Neuroimage 38, 402-412.

Diers, M., Christmann, C., Koeppe, C., Ruf, M., Flor, H., 2010. Mirrored, imagined and executed movements differentially activate sensorimotor cortex in amputees with and without phantom limb pain. Pain 149, 296-304.

Dinstein, I., Thomas, C., Behrmann, M., Heeger, D.J., 2008. A mirror up to nature. Curr. Biol. 18, R13-R18.

Downing, P.E., Jiang, Y., Shuman, M., Kanwisher, N., 2001. A cortical area selective for visual processing of the human body. Science 293, 2470-2473.

Ehrsson, H.H., Geyer, S., Naito, E., 2003. Imagery of voluntary movement of fingers, toes, and tongue activates corresponding body-part-specific motor representations. J. Neurophysiol. 90, 3304-3316.

Filimon, F., Nelson, J.D., Hagler, D.J., Sereno, M.I., 2007. Human cortical representations for reaching: mirror neurons for execution, observation, and imagery. Neuroimage 37, 1315-1328.

Filimon, F., Rieth, C.A., Sereno, M.I., Cottrell, G.W., 2014. Observed, executed, and imagined action representations can be decoded from ventral and dorsal areas. Cereb. Cortex 25, 3144-3158.

Fleming, M.K., Stinear, C.M., Byblow, W.D., 2010. Bilateral parietal cortex function during motor imagery. Exp. Brain Res. 201, 499-508.

Fourkas, A.D., Avenanti, A., Urgesi, C., Aglioti, S.M., 2006. Corticospinal facilitation during first and third person imagery. Exp. Brain Res. 168, 143-151.

Gerardin, E., Sirigu, A., Lehericy, S., Poline, J.B., Gaymard, B., Marsault, C., Agid, Y., Bihan, D., 2000. Partially overlapping neural networks for real and imagined hand movements. Cereb. Cortex 10, 1093-1104.

Goldberg, G., 1985. Supplementary motor area structure and function: review and hypotheses. Behav. Brain Sci. 8, 567-616. 
Grafton, S.T., 2009. Embodied cognition and the simulation of action to understand others. Ann. N.Y. Acad. Sci. 1156, 97-117.

Grafton, S.T., Arbib, M.A., Fadiga, L., Rizzolatti, G., 1996. Localization of grasp representations in humans by positron emission tomography. 2. Observation compared with imagination. Exp. Brain Res. 112, 103-111.

Grezes, J., Decety, J., 2001. Functional anatomy of execution, mental simulation, observation, and verb generation of actions: a meta-analysis. Hum. Brain Mapp. $12,1-19$.

Guillot, A., Collet, C., Nguyen, V.A., Malouin, F., Richards, C., Doyon, J., 2008. Functional neuroanatomical networks associated with expertise in motor imagery. Neuroimage 41, 1471-1483.

Guillot, A., Collet, C., Nguyen, V.A., Malouin, F., Richards, C., Doyon, J., 2009. Brain activity during visual versus kinesthetic imagery: an fMRI study. Hum. Brain Mapp. 30, 2157-2172.

Guillot, A., Di Rienzo, F., Macintyre, T., Moran, A., Collet, C., 2012. Imagining is not doing but involves specific motor commands: a review of experimental data related to motor inhibition. Front Hum. Neurosci. 6, 247.

Haggard, P., 2008. Human volition: towards a neuroscience of will. Nat. Rev. Neurosci. 9, 934-946.

Halsband, U., Passingham, R., 1985. Premotor cortex and the conditions for movement in monkeys (Macaca fascicularis). Behav. Brain Res. 18, 269-277.

Hanakawa, T., Dimyan, M.A., Hallett, M., 2008. Motor planning, imagery, and execution in the distributed motor network: a time-course study with functional MRI. Cereb. Cortex 18, 2775-2788.

Hassabis, D., Kumaran, D., Maguire, E.A., 2007. Using imagination to understand the neural basis of episodic memory. J. Neurosci. 27, 14365-14374.

Hayes, D.J., Huxtable, A.G., 2012. Interpreting deactivations in neuroimaging. Front. Psychol. 3, 27.

Heilman, K.M., Rothi, L.J., Valenstein, E., 1982. Two forms of ideo-motor apraxia. Neurology 32, 342-346.

Hetu, S., Gregoire, M., Saimpont, A., Coll, M.P., Eugene, F., Michon, P.E., Jackson, P.L., 2013. The neural network of motor imagery: an ALE meta-analysis. Neurosci. Biobehav Rev. 37, 930-949.

Hickok, G., 2009. Eight problems for the mirror neuron theory of action understanding in monkeys and humans. J. Cogn. Neurosci. 21, 1229-1243.

Hlustik, P., Solodkin, A., Gullapalli, R.P., Noll, D.C., Small, S.L., 2001. Somatotopy in human primary motor and somatosensory hand representations revisited. Cereb. Cortex 11, 312-321.

Hodzic, A., Kaas, A., Muckli, L., Stirn, A., Singer, W., 2009. Distinct cortical networks for the detection and identification of human body. Neuroimage 45, 1264-1271.

Holmes, P., Calmels, C., 2008. A neuroscientific review of imagery and observation use in sport. J. Mot. Behav. 40, 433-445.

Jackson, P.L., Meltzoff, A.N., Decety, J., 2006. Neural circuits involved in imitation and perspective-taking. Neuroimage 31, 429-439.

Jaffard, M., Longcamp, M., Velay, J.L., Anton, J.L., Roth, M., Nazarian, B., Boulinguez, P., 2008. Proactive inhibitory control of movement assessed by event-related fMRI. Neuroimage 42, 1196-1206.

Jeannerod, M., 1994. The representing brain: neural correlates of motor intention and imagery. Behav. Brain Sci. 17, 187-245.

Jeannerod, M., 1995. Mental imagery in the motor context. Neuropsychologia 33, $1419-1432$.

Jeannerod, M., 2001. Neural simulation of action: a unifying mechanism for motor cognition. Neuroimage 14, S103-S109.

Jeannerod, M., Decety, J., 1995. Mental motor imagery: a window into the representational stages of action. Curr. Opin. Neurobiol. 5, 727-732.

Jeannerod, M., Frak, V., 1999. Mental imaging of motor activity in humans. Curr. Opin. Neurobiol. 9, 735-739.

Jenkinson, M., Bannister, P., Brady, M., Smith, S., 2002. Improved optimization for the robust and accurate linear registration and motion correction of brain images. Neuroimage 17, 825-841.

Jenkinson, M. Smith, S., 2001. A global optimisation method for robust affine registration of brain images. Med. Image Anal. 5, 143-156.

Jiang, D., Edwards, M.G., Mullins, P., Callow, N., 2015. The neural substrates for the different modalities of movement imagery. Brain Cogn. 97, 22-31.

Kasess, C.H., Windischberger, C., Cunnington, R., Lanzenberger, R., Pezawas, L. Moser, E., 2008. The suppressive influence of SMA on M1 in motor imagery revealed by fMRI and dynamic causal modeling. Neuroimage 40, 828-837.

Kosslyn, S.M., Alpert, N.M., Thompson, W.L., Maljkovic, V., Weise, S.B., Chabris, C.F. Hamilton, S.E., Raunch, S.L., Buonanno, F.S., 1993. Visual mental imagery activates topographically organized visual cortex: PET investigations. J. Cogn. Neurosci. 5, 263-287.

Kosslyn, S.M., Thompson, W.L., Kim, I.J., Alpert, N.M., 1995. Topographical representations of mental images in primary visual cortex. Nature 378, 496-498. Kuhtz-Buschbeck, J.P., Mahnkopf, C., Holzknecht, C., Siebner, H., Ulmer, S., Jansen, O., 2003. Effector-independent representations of simple and complex imagined finger movements: a combined fMRI and TMS study. Eur. J. Neurosci. 18, 3375-3387.

Lacourse, M.G., Orr, E.L., Cramer, S.C., Cohen, M.J., 2005. Brain activation during execution and motor imagery of novel and skilled sequential hand movements. Neuroimage 27, 505-519.

Laird, A.R., Fox, P.M., Eickhoff, S.B., Turner, J.A., Ray, K.L., McKay, D.R., Glahn, D.C., Beckmann, C.F., Smith, S.M., Fox, P.T., 2011. Behavioral interpretations of intrinsic connectivity networks. J. Cogn. Neurosci. 23, 4022-4037.

Langheim, F.J.P., Callicott, J.H., Mattay, V.S., Duyn, J.H., Weinberger, D.R., 2002. Cortical systems associated with covert music rehearsal. Neuroimage 16 901-908.
Leonardo, M., Fieldman, J., Sadato, N., Campbell, G., Ibañez, V., Cohen, L., Deiber, M. P., Jezzard, P., Pons, T., Turner, R., 1995. A functional magnetic resonance imaging study of cortical regions associated with motor task execution and motor ideation in humans. Hum. Brain Mapp. 3, 83-92.

Lorey, B., Bischoff, M., Pilgramm, S., Stark, R., Munzert, J., Zentgraf, K., 2009. The embodied nature of motor imagery: the influence of posture and perspective. Exp. Brain Res. 194, 233-243.

Lotze, M., Halsband, U., 2006. Motor imagery. J. Physiol. 99, 386-395.

Lotze, M., Montoya, P., Erb, M., Hulsmann, E., Flor, H., Klose, U., Birbaumer, N., Grodd, W., 1999. Activation of cortical and cerebellar motor areas during executed and imagined hand movements: an fMRI study. J. Cogn. Neurosci. 11, 491-501.

Lotze, M., Zentgraf, K., 2010. Contribution of the primary motor cortex to motor imagery. Chapter 3, The Neurophysiological Foundations of Mental And Motor Imagery, pp. 31-45.

Madan, C.R., Singhal, A., 2012. Motor imagery and higher-level cognition: four hurdles before research can sprint forward. Cogn. Process 13, 211-229.

Molenberghs, P., Cunnington, R., Mattingley, J.B., 2012. Brain regions with mirror properties: a meta-analysis of 125 human fMRI studies. Neurosci. Biobehav. Rev. 36, 341-349.

Moran, A., 2009. Cognitive psychology in sport: progress and prospects. Psychol. Sport Exerc. 10, 420-426.

Myers, A., Sowden, P.T., 2008. Your hand or mine? The extrastriate body area Neuroimage 42, 1669-1677.

Nachev, P., Kennard, C., Husain, M., 2008. Functional role of the supplementary and pre-supplementary motor areas. Nat. Rev. Neurosci. 9, 856-869.

Nair, D.G., Purcott, K.L., Fuchs, A., Steinberg, F., Kelso, J.A., 2003. Cortical and cerebellar activity of the human brain during imagined and executed unimanual and bimanual action sequences: a functional MRI study. Brain Res. Cogn. Brain Res. 15, 250-260.

Norman, K.A., Polyn, S.M., Detre, G.J., Haxby, J.V., 2006. Beyond mind-reading: multi-voxel pattern analysis of fMRI data. Trends Cogn. Sci. 10, 424-430.

Oldfield, R.C., 1971. The assessment and analysis of handedness: the Edinburgh inventory. Neuropsychologia 9, 97-113.

Olsson, C.J., Jonsson, B., Larsson, A., Nyberg, L., 2008. Motor representations and practice affect brain systems underlying imagery: an fMRI study of internal imagery in novices and active high jumpers. Open Neuroimaging J. 2, 5-13.

Passingham, R., 1985. Premotor cortex: sensory cues and movement. Behav. Brain Res. 18, 175-185.

Passingham, R.E., Chen, Y.C., Thaller, D., 1989. Supplementary motor cortex and selfinitiated movement. In: Ito, M. (Ed.), Neural Programming. Japan Scientific Society, Tokyo, pp. 13-24.

Peelen, M.V., Downing, P.E., 2007. Using multi-voxel pattern analysis of fMRI data to interpret overlapping functional activations. Trends Cogn. Sci. 11, 4-5.

Porro, C.A., Francescato, M.P., Cettolo, V., Diamond, M.E., Baraldi, P., Zuiani, C., Bazzocchi, M., Prampero, P.E., 1996. Primary motor and sensory cortex activation during motor performance and motor imagery: a functional magnetic resonance imaging study. J. Neurosci. 16, 7688-7698.

Porro, C.A., Cettolo, V., Francescato, M.P., Baraldi, P., 2000. Ipsilateral involvement of primary motor cortex during motor imagery. Eur. J. Neurosci. 12, 3059-3063.

Ramsey, R., Cumming, J., Eastough, D., Edwards, M.G., 2010. Incongruent imagery interferes with action initiation. Brain Cogn. 74, 249-254.

Roland, P.E., Larsen, N.A., Skinhoj, E., 1980. Supplementary motor area and other cortical areas in organization of voluntary movements in man. J. Neurophysiol. 43, 118-136.

Roth, M., Decety, J., Raybaudi, M., Massarelli, R., Delon-Martin, C., Segebarth, C., Morand, S., Gemignani, A., Décorps, M., Jeannerod, M., 1996. Possible involvement of primary motor cortex in mentally simulated movement: a functional magnetic resonance imaging study. Neuroreport 7, 1280-1284.

Ruby, P., Decety, J., 2001. Effect of subjective perspective taking during simulation of action: a PET investigation of agency. Nat. Neurosci. 4, 546-550.

Sauvage, C., Poirriez, S., Manto, M., Jissendi, P., Habas, C., 2011. Reevaluating brain networks activated during mental imagery of finger movements using probabilistic Tensorial Independent Component Analysis (TICA). Brain Imaging Behav. 5, 137-148.

Schwoebel, J., Boronat, C.B., Coslett, H.B., 2002. The man who executed "imagined" movements: evidence for dissociable components of the body schema. Brain Cogn. 50, 1-16.

Sharma, N., Jones, P.S., Carpenter, T.A., Baron, J.C., 2008. Mapping the involvement of BA 4a and 4p during motor imagery. Neuroimage 41, 92-99.

Shmuel, A., Augath, M., Oeltermann, A., Logothetis, N.K., 2006. Negative functiona MRI response correlates with decreases in neuronal activity in monkey visual area V1. Nat. Neurosci. 9, 569-577.

Sirigu, A., Cohen, L.G., Duhamel, J.R., Pillon, B., Dubois, B., Agid, Y., 1995a. A selective impairment of hand posture for object utilization in apraxia. Cortex 31, 41-55.

Sirigu, A., Cohen, L., Duhamel, J.R., Pillon, B., Dubois, B., Agid, Y., Pierrot-Deseilligny, C., 1995b. Congruent unilateral impairments for real and imagined hand movements. Neuroreport 6, 997-1001.

Sirigu, A., Duhamel, J.R., Cohen, L., Pillon, B., Dubois, B., Agid, Y., 1996. The mental representation of hand movements after parietal cortex damage. Science 273 1564-1568.

Sirigu, A., Duhamel, J.R., 2001. Motor and visual imagery as two complementary but neurally dissociable mental processes. J. Cogn. Neurosci. 13, 910-919.

Smith, S.M., Zhang, Y., Jenkinson, M., Chen, J., Matthews, P.M., Federico, A., De Stefano, N., 2002. Accurate, robust, and automated longitudinal and crosssectional brain change analysis. Neuroimage $17,479-489$. 
Stephan, K., Fink, G., Passingham, R., Silbersweig, D., Ceballos-Baumann, A., Frith, C., Frackowiak, R., 1995. Functional anatomy of the mental representation of upper extremity movements in healthy subjects. J. Neurophysiol. 73, 373-386.

Sumner, P., Nachev, P., Morris, P., Peters, A.M., Jackson, S.R., Kennard, C., Husain, M. 2007. Human medial frontal cortex mediates unconscious inhibition of voluntary action. Neuron 54, 697-711.

Szameitat, A.J., McNamara, A., Shen, S., Sterr, A., 2012. Neural activation and functional connectivity during motor imagery of bimanual everyday actions. PLoS One 7.

Taylor, J.C., Wiggett, A.J., Downing, P.E., 2007. Functional MRI analysis of body and body part representations in the extrastriate and fusiform body areas. J. Neurophysiol. 98, 1626-1633.

Taylor, J.C., Downing, P.E., 2011. Division of labor between lateral and ventral extrastriate representations of faces, bodies, and objects. J. Cogn. Neurosci. 23, 4122-4137.

Urgesi, C., Berlucchi, G., Aglioti, S.M., 2004. Magnetic stimulation of Extrastriate Body Area impairs visual processing of nonfacial body parts. Curr. Biol. 14, 2130-2134.

Urgesi, C., Candidi, M., Ionta, S., Aglioti, S.M., 2007. Representation of body identity and body actions in extrastriate body area and ventral premotor cortex. Nat.
Neurosci. 10, 30-31.

Vogeley, K., Fink, G.R., 2003. Neural correlates of the first-person-perspective.

Trends Cogn. Sci. 7, 38-42

Wilson, M., 2002. Six views of embodied cognition. Psychon. Bull. Rev. 9, 625-636. Witt, S.T., Laird, A.R., Meyerand, M.E., 2008. Functional neuroimaging correlates of finger-tapping task variations: an ALE meta-analysis. Neuroimage 42, 343-356.

Wolpert, D.M., Goodbody, S.J., Husain, M., 1998. Maintaining internal representations: the role of the human superior parietal lobe. Nat. Neurosci. 1, 529-533.

Worsley, K., 2001. Statistical analysis of activation images. In: Jezzard, P., Matthews, P.M., Smith, S.M. (Eds.), Functional Magnetic Resonance Imaging: an Introduction to Methods. OUP, Oxford, pp. 251-270.

Yuan, H., Perdoni, C., Yang, L., He, B., 2011. Differential electrophysiological coupling for positive and negative BOLD responses during unilateral hand movements. J. Neurosci. 31, 9585-9593.

Zhang, H., Xu, L., Wang, S., Xie, B., Guo, J., Long, Z., Yao, L., 2011. Behavioral improvements and brain functional alterations by motor imagery training. Brain Res. 1407, 38-46.

Ziemke, T., 2003. What's that thing called embodiment. In: Proceedings of the 25th Annual meeting of the Cognitive Science Society. Lawrence Erlbaum. Mahwah, NJ, pp. 1305-1310.
67

68

69

70 